\title{
Influence of pre-diapause temperature on intensity of summer and winter diapause in the cabbage butterfly Pieris melete (Lepidoptera: Pieridae)
}

\author{
HaI-Jun XIAO, Hai-Min HE, Feng LI and FAng-SEn XUE*
}

Institute of Entomology, Jiangxi Agricultural University, Nanchang 330045, P.R. China

Key words. Pieris melete, temperature, photoperiod, aestivation, hibernation, diapause intensity

\begin{abstract}
Effect of pre-diapause temperature on summer and winter diapause intensity was examined under both laboratory and field conditions. Under short photoperiods of $8 \mathrm{~L}: 16 \mathrm{D}$ and $10 \mathrm{~L}: 14 \mathrm{D}$, all pupae entered diapause at 15,18 and $20^{\circ} \mathrm{C}$ and the incidence of diapause dropped to $82.3 \%$ and $85.5 \%$ at $22^{\circ} \mathrm{C}$, respectively. Under long photoperiods of $14 \mathrm{~L}: 10 \mathrm{D}$ and $16 \mathrm{~L}: 8 \mathrm{D}$, the incidence of diapause decreased with increasing temperature and there were significant differences among temperatures. The incidence of diapause at $16 \mathrm{~L}: 8 \mathrm{D}$ was significantly lower than that under $14 \mathrm{~L}: 10 \mathrm{D}$ at 20 and $22^{\circ} \mathrm{C}$. By transferring diapause pupae induced under various temperatures $\left(18,20\right.$ and $\left.22^{\circ} \mathrm{C}\right)$ at a short day of $10 \mathrm{~L}: 14 \mathrm{D}$ or a long day of $14 \mathrm{~L}: 10 \mathrm{D}$, to $12.5 \mathrm{~L}: 11.5 \mathrm{D}, 20^{\circ} \mathrm{C}$, the duration of summer diapause induced under $22^{\circ} \mathrm{C}$ (mean 76.1 days) was significantly shorter than those under $20^{\circ} \mathrm{C}$ (mean 85.9 days) and $18^{\circ} \mathrm{C}$ (mean 90.9 days), showing that the incidence of summer diapause was positively linked to the intensity of summer diapause; whereas the duration of winter diapause induced under $10 \mathrm{~L}: 14 \mathrm{D}$ was similar at $18^{\circ} \mathrm{C}(89.2$ days $), 20^{\circ} \mathrm{C}(88.7$ days $)$ and $22^{\circ} \mathrm{C}$ ( 89.2 days) and there were no significant differences. Field experiments also showed that the high rearing temperatures significantly decreased the incidence and intensity of summer diapause, but had no significant affect on the intensity of winter diapause. When the naturally aestivating pupae from the first spring generation (formed on 24 April) and second spring generation (formed on 15 May) were kept under summer conditions, the diapause duration of the first generation lasted for 107-166 days (mean 146 days), about twenty days longer than that of the second generation [lasted for 92-151 days (mean 126 days)]. All results reveal that the sensitivity to temperature prior to aestivation and hibernation was quite different.
\end{abstract}

\section{INTRODUCTION}

Photoperiod and temperature influence the intensity of diapause in a number of different species. These environmental factors are experienced by the pre-diapause growth stages, but their influence is expressed in the relative intensity of the ensuing diapause (Beck, 1980; Tauber et al., 1986; Danks, 1987; Koštál, 2006). Influence of temperature during diapause induction on the intensity of diapause could vary between species but also among individuals of the same species. In some species, high temperatures during diapause induction induce more intense diapause than low temperatures (Masaki, 1962, the cricket Teleogryllus emma; Sieber \& Benz, 1980, codling moth Cydia pomonella; Denlinger \& Bradfield, 1981, tobacco hornworm Manduca sexta; Beck, 1989, corn borer Ostrinia nubilalis; Wellso, 1991, Hessian fly Mayetiola destructor; Roditakis \& Karandinos, 2001, grape berry moth Lobesia botrana; Kalushkov et al., 2001, Nedvěd \& Vambera, 2002, bug Pyrrhocoris apterus; Asano et al., 2004, yellow-spotted longicorn beetle, Psacothea hilaris). In others, diapause was more intense after rearing at a low temperature (Cox, 1975, the warehouse moth Ephestia calidella; Bell 1976, Indian meal moth Plodia interpunctella; Principi et al., 1990, chrysopid Mallada flavifrons; Glitho et al., 1991, bruchid Bruchidius atrolineatus; Fantinou et al., 2003, corn stalk borer Sesamia nonagrioides). In Mamestra brassicae, the summer diapause, induced under long days, is shorter than the short-day-induced winter diapause, but its intensity is increased by high temperatures during induction (Masaki \& Sakai, 1965).

The cabbage butterfly, Pieris melete Ménétriés is multivoltine with a pupal summer and winter diapause. In the field, there are two distinct infestation peaks per year, one in spring of one generation (In some years a small proportion of the population that pupates in mid or late April can emerge and may produce a second generation) and a second in autumn of one to three generations (Xue et al., 1996). The photoperiodic response curves of $P$. melete showed an intermediate response type (Xue et al., 1997, Fig. 1). The short daylengths $(<12 \mathrm{~h})$ induced $100 \%$ winter diapause regardless of temperature. The intermediate daylengths (12 to $13.25 \mathrm{~h}$ ) induced most pupae to develop without diapause. The long daylengths $(\geq 13.5 \mathrm{~h})$ induced summer diapause and the incidence of diapause was obviously affected by both photoperiod and temperature. Influence of pre-diapause photoperiod on diapause intensity in $P$. melete was also investigated (Table 3 , in Xiao et al., 2006). The results show that the duration of diapause is significantly influenced by the pre-diapause photoperiod. At $20^{\circ} \mathrm{C}$ the durations of diapause induced by photoperiods of $12 \mathrm{~L}: 12 \mathrm{D}(65.9 \mathrm{~d}), 10 \mathrm{~L}: 14 \mathrm{D}(69.7$ d), or $8 \mathrm{~L}: 16 \mathrm{D}(68.1 \mathrm{~d})$ were significantly shorter than at 13L : 11D, (94.5 d), 14L : 10D (102.8 d), or 16L : 8D $(80.6 \mathrm{~d})$. There were no significant differences in the intensity of diapause induced by short photoperiods of

\footnotetext{
* Corresponding author; e-mail: fangsen@nc.jx.cn
} 
TABLE1. A comparison of diapause incidence and duration of diapause (mean $\pm \mathrm{SE}$ ) in P. melete when the different generations of larvae hatched at different times were reared under natural conditions. Diapausing pupae were kept at $12.5 \mathrm{~L}: 11.5 \mathrm{D}, 20^{\circ} \mathrm{C}$ to terminate diapause.

\begin{tabular}{|c|c|c|c|c|c|}
\hline & Day-length $^{1}$ & Temperature ${ }^{2}\left({ }^{\circ} \mathrm{C}\right)$ & No. of pupae observed & Diapause (\%) & Duration of diapause $^{3}(\mathrm{n})$ \\
\hline SG1 & 12 h 57 min -13 h 49 min & 18.6 & 5720 & 98.13 & $93.24 \pm 1.45(136) \mathrm{a}$ \\
\hline SG2 & $14 \mathrm{~h} 05 \mathrm{~min}-14 \mathrm{~h} 43 \mathrm{~min}$ & 21.2 & 1211 & 94.55 & $86.70 \pm 1.32(118) b$ \\
\hline SG3 & $14 \mathrm{~h} 43 \mathrm{~min}-14 \mathrm{~h} 56 \mathrm{~min}$ & 25.0 & 154 & 10.38 & $70.07 \pm 4.59(14) c$ \\
\hline AG1 & $13 \mathrm{~h} 22 \mathrm{~min}-12 \mathrm{~h} 30 \mathrm{~min}$ & 24.3 & 757 & 1.59 & - \\
\hline AG2 & $12 \mathrm{~h} 30 \mathrm{~min}-11 \mathrm{~h} 59 \mathrm{~min}$ & 21.9 & 721 & 89.60 & $94.24 \pm 1.49(119) \mathrm{a}$ \\
\hline AG3 & $11 \mathrm{~h} 43 \mathrm{~min}-11 \mathrm{~h} 11 \mathrm{~min}$ & 14.6 & 738 & 100 & $90.64 \pm 1.51(140) \mathrm{a}$ \\
\hline
\end{tabular}

${ }^{1}$ Natural day-length from day of hatching to pupation (including twilight); ${ }^{2}$ the mean natural temperature from the day of hatching to pupation; ${ }^{3}$ values followed by different letters are significantly different based on one-way analysis of variance (ANOVA) and a multiple Bonferroni test.

12L : 12D, 10L : 14D and 8L : 16D, whereas differences induced by the long photoperiods of $13 \mathrm{~L}: 11 \mathrm{D}, 14 \mathrm{~L}$ : $10 \mathrm{D}$ and $16 \mathrm{~L}: 8 \mathrm{D}$ were significantly different.

So far, the influence of pre-diapause temperature on the intensity of summer diapause has been investigated only in a few insects. However, $P$. melete is an excellent animal for studying the influence of pre-diapause temperature on diapause intensity, as summer diapause is highly sensitive to temperature. It is therefore of interest to examine whether pre-diapause temperature has a significant influence on diapause intensity.

\section{MATERIAL AND METHODS}

In the experiments we used specimens collected from the suburbs of Nanchang $\left(28^{\circ} 46^{\prime} \mathrm{N}, 115^{\circ} 50^{\prime} \mathrm{E}\right.$, about $50 \mathrm{~m}$ a.s.l.), Jiangxi Province, P.R. China. Full-grown larvae prior to pupation were collected from wild crucifers in late November 2005 and transferred to wooden insectaries $(30 \times 30 \times 35 \mathrm{~cm})$ to pupate and overwinter under natural condition. Adults emerged in spring 2006 and were transferred to an outdoor screened insectary for mating and oviposition. The eggs were collected, placed in incubators and the newly hatched larvae were reared in round plastic boxes $(7.5 \times 6 \mathrm{~cm})$ each containing fresh Chinese cabbage (B. juncae var. communis) leaves and at least 50 larvae. When the larvae reached the fifth instar, they were transferred to two boxes to pupate.

In order to determine whether diapause incidence is linked to diapause intensity, the incidence of diapause in larvae reared under two short photoperiods of 8L : 16D and 10L : 14D (for the induction of winter diapause) and two long photoperiods of $14 \mathrm{~L}: 10 \mathrm{D}$ and $16 \mathrm{~L}: 8 \mathrm{D}$ (for the induction of summer diapause) at $15,18,20$ and $22^{\circ} \mathrm{C}$ until they pupated, was recorded. All treatments were repeated three times. Then the diapausing pupae induced by the short photoperiod of 10L : 14D or long photoperiod of $14 \mathrm{~L}: 10 \mathrm{D}$ at 18,20 and $22^{\circ} \mathrm{C}$ were transferred to $12.5 \mathrm{~L}: 11.5 \mathrm{D}, 20^{\circ} \mathrm{C}$ to terminate diapause. The criterion of diapause termination was adult emergence; and the duration of diapause included the period of post-diapause development.

To examine the effects of seasonal variations on the incidence and duration of summer and winter diapause, the adults from the overwintering pupae were released into an outdoor screened insectary for reproduction. From this insectary we obtained 107 non-diapausing pupae from the 5720 pupae of the first spring generation (SG1). We successfully reared another two successive spring generations, using these non-diapausing pupae, in this outdoor screened insectary under natural conditions and obtained three different generations of aestivating pupae. The first spring generation that pupated on 24 April (as SG1), second generation on 15 May (as SG2) and third generation on 15 June (as SG3) were selected for diapause termination (Table 1). On the tenth day after pupation, those aestivating pupae were divided into two groups. In one group, aestivating pupae from SG1, SG2 and SG3 were transferred to round plastic boxes and kept under a diapause-preventing photoperiod of $12.5 \mathrm{~L}: 11.5 \mathrm{D}$ at $20^{\circ} \mathrm{C}$ to terminate diapause. In other group, aestivating pupae from SG1 and SG2 were maintained under natural conditions to terminate diapause.

In autumn, we also successfully reared three successive autumn generations (as AG1, the first autumn generation, AG2 and AG3, respectively, Table 1) by using the adults from aestivating pupae in this outdoor screened insectary under natural conditions. As a few individuals entered diapause in AG1, only the diapausing pupae from AG2 and AG3 were used to record the termination of diapause at $12.5 \mathrm{~L}: 11.5 \mathrm{D}, 20^{\circ} \mathrm{C}$.

Laboratory experiments were performed in illuminated incubators (LRH-250-GSII) with adjustable temperature and photoperiod. The incubators were equipped with four fluorescent 30 W tubes controlled by an automatic time switch. Light intensity at the level of the insects was about $700 \mathrm{~lx}$ and the variation in temperature was $\pm 0.5^{\circ} \mathrm{C}$.

Statistical analyses were conducted using the STATA package Version 9.0. Bonferroni test $(P=0.05)$ was used to

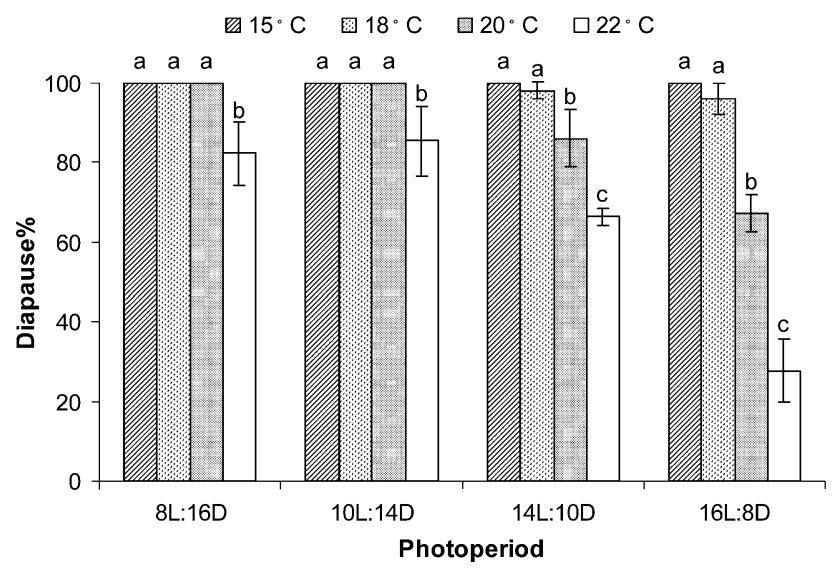

Fig. 1. Diapause incidence of aestivation and hibernation induced at different photoperiods and constant temperatures. Values followed by different letters are significantly different based on Bonferroni test and one-way analysis of variance (ANOVA) $(\mathrm{F}=14.75$, d.f. $=3,8, P=0.0013$ for $8 \mathrm{~L}: 16 \mathrm{D}, \mathrm{F}=$ 8.44, d.f. $=3,8, P=0.0073$ for $10 \mathrm{~L}: 14 \mathrm{D}, \mathrm{F}=36.93$, d.f. $=3$, $8, P=0.0000$ for $14 \mathrm{~L}: 10 \mathrm{D}$ and $\mathrm{F}=137.56$, d.f. $=3,8, P=$ 0.0000 for $16 \mathrm{~L}: 8 \mathrm{D}) . \mathrm{n}=47-167$ for each treatment. 

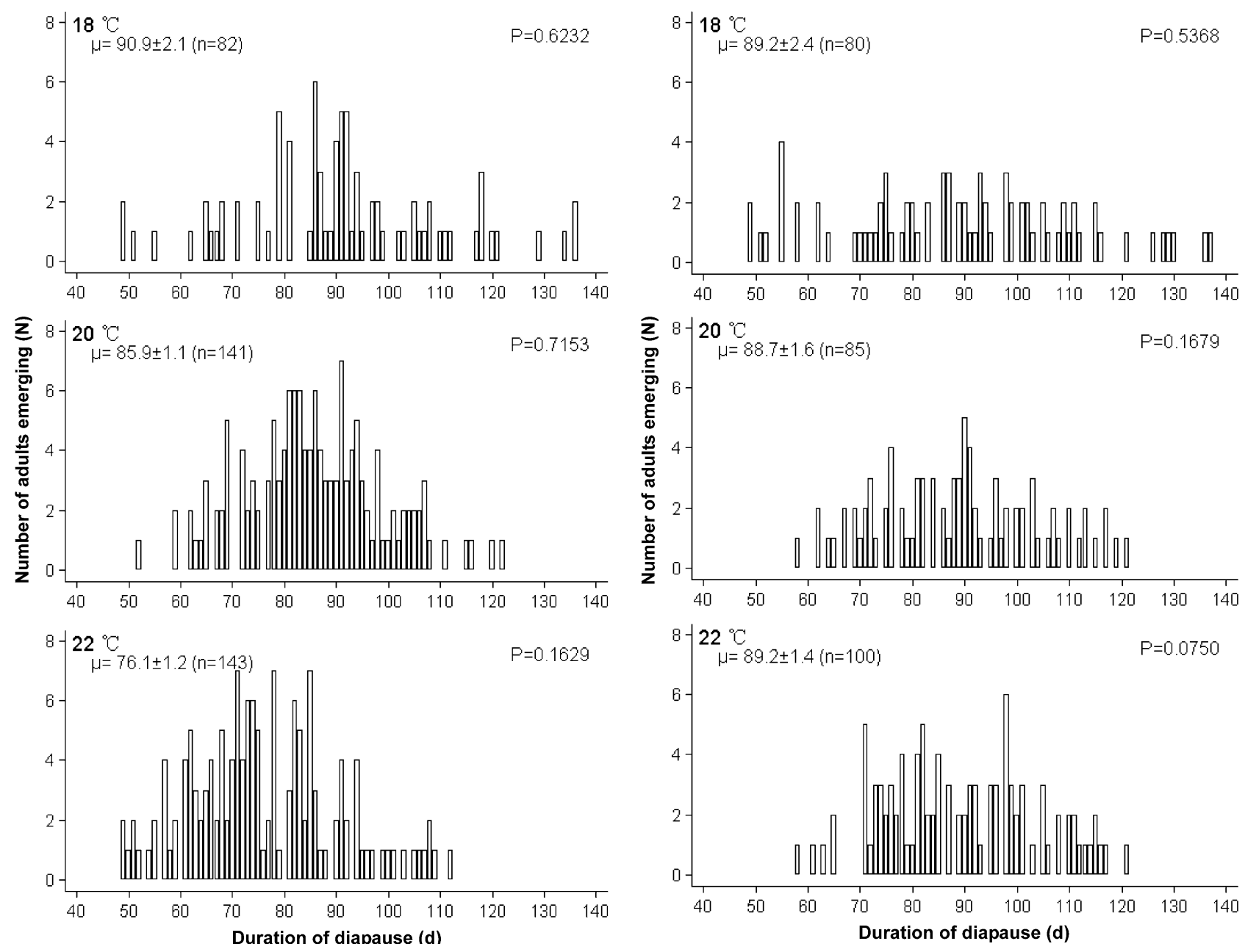

Fig. 2. Duration of summer diapause at $12.5 \mathrm{~L}: 11.5 \mathrm{D}, 20^{\circ} \mathrm{C}$ in $P$. melete. Diapause was induced under $14 \mathrm{~L}: 10 \mathrm{D}$, at $18^{\circ} \mathrm{C}$, $20^{\circ} \mathrm{C}$ and $22^{\circ} \mathrm{C}$.

determine whether the variance in the incidence of diapause in the different temperature and photoperiodic regimes treatment were significant. Date for the duration of diapause was tested for normality using Skewness/Kurtosis tests. One-way analysis of variance (ANOVA) and Bonferroni multiple comparison at $P$ $=0.05$ was used to determine whether differences in the duration of diapause among different generations and treatments were significant.

\section{RESULTS}

\section{Effect of temperature on the induction of summer and winter diapause}

Effect of temperature on the incidence of diapause was quite different for winter and summer diapause (Fig. 1). Under short photoperiods of $8 \mathrm{~L}: 16 \mathrm{D}$ and $10 \mathrm{~L}: 14 \mathrm{D}$, all pupae entered diapause at 15,18 and $20^{\circ} \mathrm{C}$. The incidence of diapause dropped to $82.3 \%$ under $8 \mathrm{~L}$ : $16 \mathrm{D}$ and $85.5 \%$ under 10L: $14 \mathrm{D}$ at $22^{\circ} \mathrm{C}$, but there was no significant difference between these two treatments [Bonferroni test: $P$ $(=0.6564)>0.05]$. However, under long photoperiods of $14 \mathrm{~L}: 10 \mathrm{D}$ and $16 \mathrm{~L}: 8 \mathrm{D}$, the incidence of diapause decreased with increasing temperature $(100 \%$ at 15 and $18^{\circ} \mathrm{C}, 86.2 \%$ at $20^{\circ} \mathrm{C}$, and $66.4 \%$ at $22^{\circ} \mathrm{C}$ under $14 \mathrm{~L}$ : $10 \mathrm{D} ; 100 \%$ at $15^{\circ} \mathrm{C}, 95.9 \%$ at $18^{\circ} \mathrm{C}, 67.3 \%$ at $20^{\circ} \mathrm{C}$, and

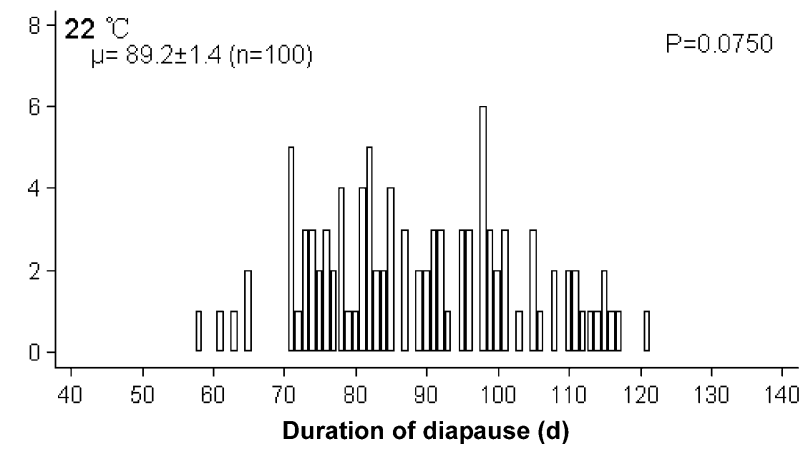

Fig. 3. Duration of winter diapause at $12.5 \mathrm{~L}: 11.5 \mathrm{D}, 20^{\circ} \mathrm{C}$ in P. melete. Diapause was induced under $10 \mathrm{~L}: 14 \mathrm{D}$, at $18^{\circ} \mathrm{C}$, $20^{\circ} \mathrm{C}$ and $22^{\circ} \mathrm{C}$.

$27.8 \%$ at $22^{\circ} \mathrm{C}$ under $\left.16 \mathrm{~L}: 8 \mathrm{D}\right)$ and there were significant difference among temperatures $[\mathrm{F}=36.93$, d.f. $=3,8, P$ $(=0.0000)<0.01$ for $14 \mathrm{~L}: 10 \mathrm{D}$ and $\mathrm{F}=137.56$, d.f. $=$ $3,8, P(=0.0000)<0.01$ for $16 \mathrm{~L}: 8 \mathrm{D})$. Statistical analyses also showed that the incidence of diapause at $16 \mathrm{~L}: 8 \mathrm{D}$ was significantly lower than under $14 \mathrm{~L}: 10 \mathrm{D}$ at 20 and $22^{\circ} \mathrm{C}$ (Bonferroni test: $P=0.008$ at $20^{\circ} \mathrm{C}, P=$ 0.022 at $22^{\circ} \mathrm{C}$ ).

\section{Effect of pre-diapause temperature on summer and winter diapause intensity}

The differences among the durations of pupal diapause induced under various temperatures $\left(18,20\right.$ and $\left.22^{\circ} \mathrm{C}\right)$ at a short day of $10 \mathrm{~L}: 14 \mathrm{D}$ or a long day of $14 \mathrm{~L}: 10 \mathrm{D}$ were examined at $20^{\circ} \mathrm{C}, 12.5 \mathrm{~L}: 11.5 \mathrm{D}$ (Fig. 2 and Fig. 3 ). The duration of summer diapause induced by $22^{\circ} \mathrm{C}$ (mean $76.1 \pm 1.2$ days) was significantly shorter than those by $20^{\circ} \mathrm{C}$ (mean $85.9 \pm 1.1$ days) and $18^{\circ} \mathrm{C}$ (mean $90.9 \pm 2.1$ days $)(\mathrm{F}=29.00$, d.f. $=2,363, P(=0.0000)<0.01$; Bonferroni test: $P=0.000$ between 20 as well as $18^{\circ} \mathrm{C}$ and $22^{\circ} \mathrm{C}, P=0.049$ between $18^{\circ} \mathrm{C}$ and $20^{\circ} \mathrm{C}$ ) (Fig. 2). However, the duration of winter diapause induced under $10 \mathrm{~L}$ : $14 \mathrm{D}$ was similar at $18^{\circ} \mathrm{C}(89.2 \pm 1.4$ days $), 20^{\circ} \mathrm{C}(88.7 \pm$ 1.6 days) and $22^{\circ} \mathrm{C}(89.2 \pm 2.4$ days $)$, and there were no 


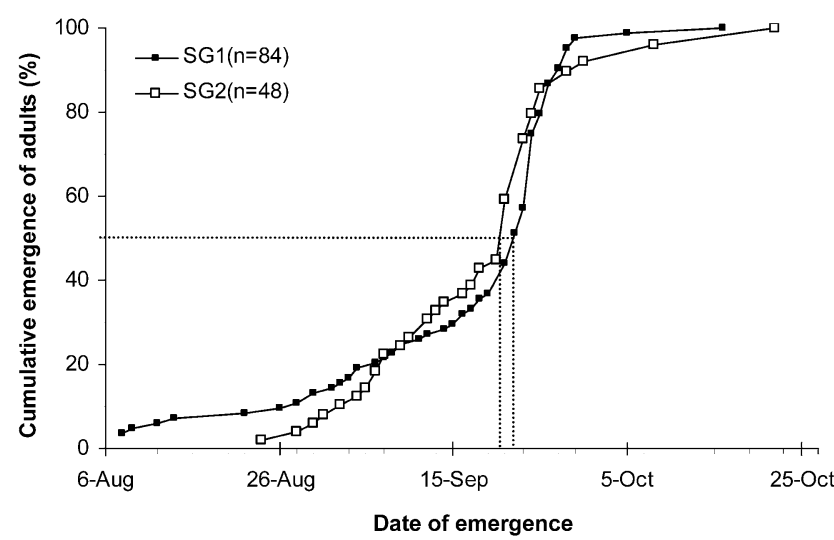

Fig. 4. Diapause termination of aestivating pupae from the first spring generation (formed on 24 April) and second spring generation (formed on 15 May) under natural conditions.

significant differences $(\mathrm{F}=0.02$, d.f. $=2,262, P(=$ $0.9795)>0.05$; Bonferroni test: $P=1.000$ between all of the three treatments) (Fig. 3). These results indicate that high rearing temperature decreased the intensity of summer diapause, but did not significantly influence the intensity of winter diapause.

The incidence of summer and winter diapause in three successive spring and autumn generations under natural conditions and their diapause termination at 12.5L : 11.5D and $20^{\circ} \mathrm{C}$

Table 1 shows the effects of naturally changing photoperiods and temperatures on diapause incidence and subsequent diapause intensity. In spring generations, the incidence of diapause as well as diapause intensity gradually declined with increasing daylengths and temperatures. The incidence of diapause in three successive spring generations was $98.13 \%, 94.55 \%$ and $10.38 \%$, respectively. The duration of diapause induced under $25.0^{\circ} \mathrm{C}(70.1 \mathrm{~d})$ was significantly shorter than that at $21.2^{\circ} \mathrm{C}(86.7 \mathrm{~d})$ or at $18.6^{\circ} \mathrm{C}(93.2 \mathrm{~d})(\mathrm{F}=15.97$, d.f. $=2$, 265, $P(=0.0000)<0.01$; Bonferroni test: $P=0.001$ between $25.0^{\circ} \mathrm{C}$ and $21.2^{\circ} \mathrm{C}$ and $P=0.000$ between $25.0^{\circ} \mathrm{C}$ and $\left.18.6^{\circ} \mathrm{C}\right)$. In autumn generations, percentage of diapause gradually increased as the daylengths and temperatures decreased. In AG1, only $1.59 \%$ individuals entered diapause when they were exposed to intermediate daylengths (13 h $22 \mathrm{~min}$ to $12 \mathrm{~h} 30 \mathrm{~min}$ ) and a high mean temperature of $24.3^{\circ} \mathrm{C}$ during mid to late September, the incidence of diapause in the second and third autumn generations, was increased to $89.60 \%$ and $100 \%$, respectively. However, there were no significant differences in diapause intensity between AG2 and AG3 (F = 2.86, d.f. $=1,257, P(=0.092)>0.05)$, although the rearing temperature was quite different between $\mathrm{AG} 2\left(21.9^{\circ} \mathrm{C}\right)$ and AG3 $\left(14.6^{\circ} \mathrm{C}\right)$. These results further indicate that high rearing temperatures decrease the intensity of summer diapause, but did not significantly influence the intensity of winter diapause.

\section{Duration of summer diapause under natural conditions}

When the naturally aestivating pupae from the first spring generation (formed on 24 April, diapause induced under the daylengths from $12 \mathrm{~h} 57 \mathrm{~min}$ to $13 \mathrm{~h} 49 \mathrm{~min}$ and $18.6^{\circ} \mathrm{C}$ ) and second generation (formed on 15 May, diapause induced under the daylengths from $14 \mathrm{~h} 5 \mathrm{~min}$ to $14 \mathrm{~h} 43 \mathrm{~min}$ and $21.2^{\circ} \mathrm{C}$ ) were kept under summer conditions, the diapause duration of the first generation lasted for 107-166 days (mean 146 days), about twenty days longer than that of the second generation [lasted for 92-151 days (mean 126 days)]. However, the period of adult emergence from both groups of aestivating pupae was almost synchronized. The date of emergence of 50\% of the individuals occurred between 21 (for SG2) and 22 (SG1) September for aestivating pupae of both generations (Fig. 4).

\section{DISCUSSION}

High temperature is generally reported to enhance induction of summer diapause (Masaki, 1980; Tauber et al., 1986; Danks, 1987). However, high temperature strongly weakened the diapause-inducing effects of long daylengths in $P$. melete and resulted in a low incidence of diapause (Fig. 1). Furthermore, the incidence of summer diapause was positively linked to the intensity of summer diapause. The lower the incidence of diapause, the shorter the duration of diapause (Fig. 2, Table 1).

The influence of pre-diapause temperature on winter diapause intensity/duration has been studied in a number of insects (see Introduction), but there are few studies on summer diapause. The intensity of the pupal summer diapause in the noctuids $M$. brassicae and M. oleracea, is increased by rearing the larvae under long days at a high temperature (Masaki \& Sakai, 1965; Poitout \& Bues 1977). In the ten-spotted lady beetle Epilachna admirabilis, rearing temperatures of $20-30^{\circ} \mathrm{C}$ did not affect the intensity of summer diapause (Imai, 2004). In the zygaenid moth, Pseudopidorus fasciata, the duration of prepupal summer diapause induced under 25 and $28^{\circ} \mathrm{C}$ is similar at $25^{\circ} \mathrm{C}, 13 \mathrm{~L}: 11 \mathrm{D}$ (Wu et al., 2006, Table 2). Unlike the above species, the duration of summer diapause in $P$. melete decreased with increasing temperature in both the laboratory (Fig. 2) and under natural conditions (Table 1). The high rearing temperatures significantly decreased diapause intensity compared to relatively low temperatures. Such a mechanism may serve to synchronize emergence between the early diapause and laterdiapause individuals in autumn. Field observations support this (Fig. 4). The aestivating pupae formed on 24 April underwent a long summer diapause (mean 146 days), whereas those formed on 15 May underwent a short diapause (mean 126 days). However, adults from both mainly emerged during the same period, end of August to mid-October.

As diapause incidence is mostly linked to diapause intensity, one would expect that the action of low temperatures during induction of winter diapause would strengthen diapause. In $E$. calidella, diapause is more 
intense when induced (by short days) at $20^{\circ} \mathrm{C}$ rather than $30^{\circ} \mathrm{C}$ (Cox, 1975). In M. flavifrons, the $3^{\text {rd }}$ instar larvae have a diapause twice as long after induction in the $2^{\text {nd }}$ instar at $15^{\circ} \mathrm{C}$ than at $25^{\circ} \mathrm{C}$ (Principi et al., 1990). In $S$. nonagrioides, the number of days needed for $50 \%$ of diapausing larvae to pupate is much less when the larvae are reared at $25^{\circ} \mathrm{C}$ than at $20^{\circ} \mathrm{C}$ (Fantinou et al., 2003). However, pre-diapause temperature did not affect the intensity of winter diapause in $P$. melete. The duration of the different hibernating generations was almost the same (AG2, 94 days and AG3, 91 days) (Table 1). According to our recent experiments, the rate of diapause development during winter diapause was strongly affected by low temperature during diapause. Low temperature obviously enhanced the development and termination of winter diapause. For example, when the naturally induced hibernating pupae were exposed to a low temperature of $5^{\circ} \mathrm{C}$ for 60 days and then transferred to $12.5 \mathrm{~L}: 11.5 \mathrm{D}, 20^{\circ} \mathrm{C}$ to terminate diapause, the mean diapause duration (75.3 days) was significantly shorter than that (94.2 days) when they were kept under $12.5 \mathrm{~L}: 11.5 \mathrm{D}, 20^{\circ} \mathrm{C}$ without prior exposure to a temperature of $5^{\circ} \mathrm{C}$.

All our results indicate that the sensitivity to temperature prior to aestivation and hibernation is quite different in $P$. melete.

ACKNOWLEDGEMENTS. The research was supported by a grant from National Natural Science Foundation of P.R. China (30760034).

\section{REFERENCES}

Asano W., Munyiri F., Shintani Y. \& Ishikawa Y. 2004: Interactive effects of photoperiod and temperature on diapause induction and termination in the yellow-spotted longicorn beetle, Psacothea hilaris. Physiol. Entomol. 29: 458-463.

BeCK S.D. 1980: Insect Photoperiodism. 2nd ed. Academic Press, New York, 397 pp.

BECK S.D. 1989: Factors influencing the intensity of larval diapause in Ostrinia nubilalis. J. Insect Physiol. 35: 75-79.

Bell C.H. 1976: Factors influencing the duration and termination of diapause in the Indian meal moth, Plodia interpunctella. Physiol. Entomol. 1: 169-178.

Cox P.H. 1975: The influence of photoperiod on the life cycles of Ephestia calidella (Guenée) and Ephestia figuliella Gregson (Lepidoptera: Phyticidae). J. Stored Prod. Res. 11: $75-86$.

Danks H.V. 1987: Insect Dormancy: An Ecological Perspective. Biological Survey of Canada, Ottawa, $439 \mathrm{pp}$.

Denlinger D.L. \& Bradfield J.Y. 1981: Duration of pupal diapause in the tobacco hornworm is determined by number of short days received by the larva. J. Exp. Biol. 91: 331-337.

Fantinou A.A., Kourti A.T. \& Saitanis C. 2003: Photoperiodic and temperature effects on the intensity of larval diapause in Sesamia nonagrioides. Physiol. Entomol. 88: 82-87.

Glitho I.A., Lenga A. \& Huignard J. 1991: Intensity of the male reproductive diapause in Bruchidius atrolineatus Pic
(Coleoptera: Bruchidae) is affected by induction conditions. Invert. Reprod. Dev. 19: 233-243.

IMAI C. 2004: Photoperiodic induction and termination of summer diapause in adult Epilachna admirabilis (Coleoptera: Coccinellidae) from a warm temperature region. Eur. J. Entomol. 101: 523-529.

Kalushiov P., Hodková M., Nedvěd O. \& Hodek I. 2001: Effect of thermoperiod on diapause intensity in Pyrrhocoris apterus (Heteroptera: Pyrrhocoridae). J. Insect Physiol. 47: $55-61$.

KošTÁL V. 2006: Eco-physiological phases of insect diapause. $J$. Insect Physiol. 52: 113-127.

MASAKI S. 1962: The influence of temperature on the intensity of diapause in the eggs of the Emma field cricket (Orthoptera: Gryllidae). Kontyu 30: 9-16.

Masaki S. 1980: Summer diapause. Annu. Rev. Entomol. 25: $1-25$.

MASAKI S. \& SAKAI T. 1965: Summer diapause in the seasonal lifecycle of Mamestra brassicae (Linné). Jap. J. Appl. Entomol. Zool. 9: 191-205.

NedVĚD O. \& VAmbera J. 2001: Does low rearing temperature increase diapause intensity in Pyrrhocoris apterus? Acta Soc. Zool. Bohem. 65: 263-267.

Poitout S. \& Bues R. 1977: Études comparées de diapauses nymphales estivales existant dans les populations de basse vallée du Rhône de deux Noctuidae Hadeninae (Mamestra brassicae L., Mamestra oleracea L.). Ann. Zool. Ecol. Anim. 9: $225-234$.

Principi M.M., Memmi M. \& Sgobba D. 1990: Effects of temperature on larval diapause of Mallada flavifrons (Brauer) (Neuroptera: Chrysopidae). Boll. Ist. Entomol. Guido Grandi, Univ. Bologna 44: 37-55 [in Italian, English abstr].

Roditakis N. \& Karandinos M. 2001: Effect of photoperiod and temperature on pupal diapause induction of grape berry moth Lobesia botrana. Physiol. Entomol. 26: 329-340.

Sieber R. \& BEnz G. 1980: Termination of the facultative diapause in the codling moth, Laspeyresia pomonella (Lepidoptera: Tortricidae). Entomol. Exp. Appl. 28: 204-222.

Tauber M.J., Tauber C.A. \& Masaki S. 1986: Seasonal Adaptations of Insect. Oxford University Press, New York and Oxford, $411 \mathrm{pp}$.

WelLso S.G. 1991: Aestivation and phenology of the hessian fly (Diptera: Cecidomyiidae) in Indiana. Envir. Entomol. 20: 795-801.

Wu S.H., YANG D., LAI X.T. \& XUE F.S. 2006: Induction and termination of prepupal summer diapause in Pseudopidorus fasciata (Lepidoptera: Zygaenidae). J. Insect Physiol. 52: 1095-1104.

Xiao H.J., Yang D. \& Xue F.S. 2006: Effect of photoperiod on duration of summer and winter diapause in the cabbage butterfly, Pieris melete (Lepidoptera: Pieridae). Eur. J. Entomol. 103: $537-540$.

Xue F.S. Zhu X.F. \& Wei H.Y. 1996: Biology of Pieris melete Ménétriés. Jiangxi Plant Prot. 19: 1-4 [in Chinese].

Xue F.S., Kallenborn H.G. \& Wei H.Y. 1997: Summer and winter diapause in pupae of the cabbage butterfly, Pieris melete Ménétriés. J. Insect Physiol. 43: 701-707.

Received October 29, 2007; revised and accepted December 4, 2007 